\title{
Gradhiva
}

GRADHIV

Revue d'anthropologie et d'histoire des arts

$32 \mid 2021$

Livres sorciers

\section{Passeport pour le Ciel. Prophétisme et bureaucratie au Congo (1921-1960)}

A Passport to Heaven. Prophecy and Bureaucracy in Congo (1921-1960)

Julien Bonhomme

\section{(2) OpenEdition}

1 Journals

Édition électronique

URL : https://journals.openedition.org/gradhiva/5558

DOI : 10.4000/gradhiva.5558

ISSN : 1760-849X

Éditeur

Musée du quai Branly Jacques Chirac

Édition imprimée

Date de publication : 24 mars 2021

Pagination : 124-143

ISBN : 978-2-35744-132-3

ISSN : 0764-8928

Référence électronique

Julien Bonhomme, «Passeport pour le Ciel. Prophétisme et bureaucratie au Congo (1921-1960)», Gradhiva [En ligne], 32 | 2021, mis en ligne le 02 avril 2021, consulté le 25 mai 2021. URL : http://

journals.openedition.org/gradhiva/5558; DOI : https://doi.org/10.4000/gradhiva.5558

() musée du quai Branly 


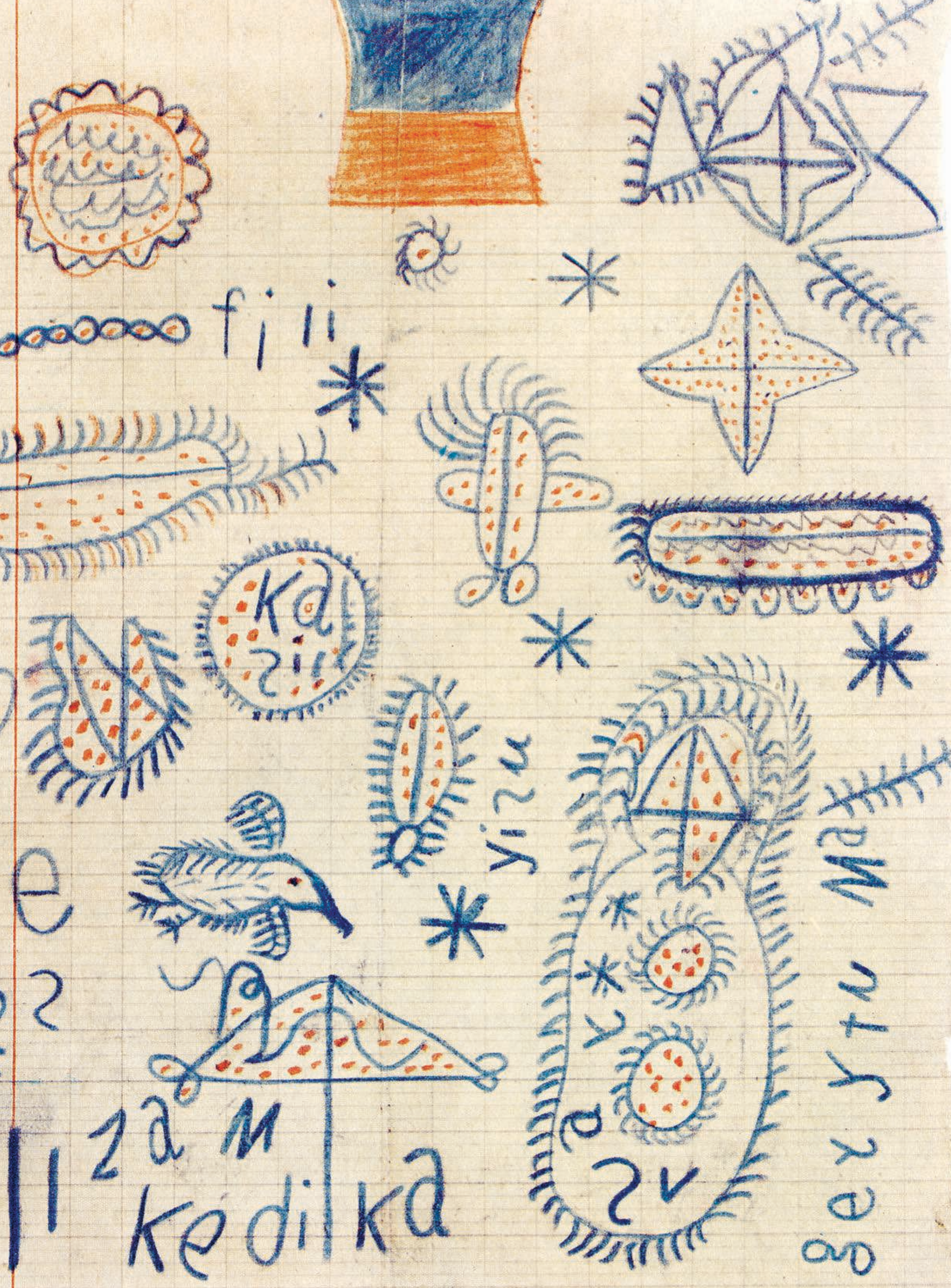


Passeport

pour le Ciel

Prophétisme

et bureaucratie

au Congo

(1921-1960) 
Cet article étudie les rapports entre religion, écriture et pouvoir en contexte colonial, en examinant un corpus de documents appelés «passeports pour le Ciel», en usage dans les prophétismes kongo de la première moitié du xx siècle. Dans le bassin du Congo, l'écrit est associé à ces deux piliers de l'ordre colonial que sont l'État et les congrégations missionnaires. C'est dans ce contexte qu'il faut replacer l'usage de ces documents prophétiques. L'article montre comment l'écrit participe à la construction de l'autorité à la croisée des sphères politique et religieuse. Fusionnant le messianisme et la bureaucratie, les «passeports pour le Ciel» attestent d'une compréhension lucide des ressorts scripturaires de l'autorité coloniale. C'est parce que les Européens ont utilisé l'écrit pour asseoir leur domination que les sujets colonisés se sont approprié de manière mimétique ces signes de pouvoir afin de s'opposer à elle.

1. Fonds du Gouvernement général du Congo belge (GG17702).

2. Le «Bas-Congo» correspond à la province du Kongo central dans le découpage administratif de l'actuelle République démocratique du Congo.

3. Fonds du Gouv. $G^{\text {al }}$ du Congo belge (GG16203). Les «tickets» mentionnés dans la circulaire désignent les passeports pour le Ciel. Comme la plupart des écrits prophétiques, le document était rédigé en kikongo, mais seule sa traduction française figure dans les archives.

4. Sur le sujet, mais concernant le monde amérindien, voir: Déléage 2013; 2017
En mars 1944 à Léopoldville, capitale du Congo belge, l'administrateur Van Droogenbroeck fait saisir un ensemble de documents lors de l'arrestation de membres de la Mission des Noirs, une Église indépendante qualifiée de «secte politico-reliǵieuse» par les autorités. Dans le lot figurent deux «passeports pour le Ciel » qui se trouvent encore dans un dossier du fonds des archives africaines à Bruxelles ${ }^{\mathbf{1}}$ (fig. 3). Il s'agit de petits billets manuscrits intitulés nkanda $n \approx i l a$ zulu, littéralement «papiers du chemin du Ciel » en kikongo. Chaque exemplaire précise l'identité du titulaire, le nom de l'éǵlise locale, la date et le lieu d'établissement du document. En dessous, à l'encre rouge, un $\mathrm{S}$ assorti du dessin stylisé d'un visage. Lors de son interrogatoire, le secrétaire de l'Éǵlise expliquait qu'il s'agissait de la signature du prophète Simon Kimbangú, emprisonné depuis 1921.

Dans les années 1940, de nombreux passeports du même genre sont découverts par les aǵents du gouvernement dans toute la région du Bas-Congo ${ }^{2}$, mais aussi de l'autre côté du fleuve, en territoire français (fig. 1). D'autres documents les accompaǵnent parfois et y font référence. Une «circulaire» saisie en 1945 au sein d'une cellule prophétique et siǵnée «Moi S.B.M. Bola-Mananga Simon Kimbangu » annonce sur un ton apocalyptique:

Maintenant, je pars chez le Père pour la nouvelle vie et à mon retour je deviendrai votre chef pour vous montrer le chemin de Jérusalem. Vous mourrez beaucoup, puisque vous êtes encore dans l'obscurité. D'ici peu de temps, vos jeunes suivront. Alors vous verrez que notre Congo sera gouverné par votre Dieu et Roi: Simon Kimbangu, qui deviendra Dieu toutpuissant. Pour avoir le triple de la vie éternelle, il faut laver vos uniformes, préparez vos tickets et lorsque le moment viendra, je me mettrai à côté du Père. Il est temps pour vous, mais pas pour les Européens. Entraîne: hommes, femmes et enfants pour le travail de notre Dieu. Et inscrivez leurs noms ${ }^{3}$.

Ces documents prophétiques offrent l'occasion d'étudier les rapports entre religion, écriture et pouvoir en contexte colonial ${ }^{4}$. L'Afrique de cette période a vu naître de nombreux mouvements reliǵieux accordant un statut spécial à l'écrit, ce que l'on peut appeler, à la suite d'Amselle (2001: 77-80), des «prophétismes scripturaires». Le motif de l'écriture révélée est un de leurs principaux thèmes: les prophètes reçoivent la vision d'un Livre sacré; ils inventent de nouvelles écritures plus ou moins indéchiffrables; leurs révélations sont couchées sur le papier par des secrétaires attitrés. À travers l'écriture, c'est l'autorité qui lui est associée que les prophètes cherchent à capter afin d'accroître leur prestige (Probst 1989).

La question des pouvoirs conférés à l'écriture (et des pouvoirs qu'elle procure) ne peut être envisagée in abstracto, car elle dépend des contextes sociohistoriques dans lesquels les documents sont produits et circulent: l'écriture est toujours prise dans des rapports sociaux qui en déterminent le sens, la valeur et les effets (Street 1984). À cet égard, l'idéologie de l'écriture à l'origine des prophétismes scripturaires est inséparable de la situation coloniale. Instrument de pouvoir autant que de savoir, l'écrit a joué un rôle essentiel dans la colonisation de l'Afrique (Hawkins 2002 ; Madeira Santos 2010). Dans le bassin du Congo, il est étroitement associé à ces deux piliers de l'ordre colonial que sont l'État et les congrégations missionnaires. Les sujets colonisés ont fait l'expérience 
du pouvoir de l'écrit par le biais de la Bible, mais aussi à travers toute une masse de documents administratifs: titres de propriété, livrets d'identité, reçus d'impôt, procès-verbaux de police 5 . Ce qui est en jeu, ce n'est donc pas l'écriture en tant que telle, mais certains types d'écrits et les institutions qui les produisent.

C'est dans ce contexte qu'il faut replacer les usages de l'écrit dans le prophétisme congolais de la première moitié du $\mathrm{xx}^{\mathrm{e}}$ siècle. Les travaux consacrés à l'appropriation religieuse de l'écriture dans les sociétés extra-européennes ont tendance à focaliser l'attention sur des situations de contact récent ou sur des populations majoritairement illettrées. Le risque est alors de «fétichiser» l'écriture en laissant croire que ces sociétés auraient été incapables d'appréhender ce nouveau médium autrement qu'à travers les œillères traditionnelles d'une pensée magico-religieuse: comme si, au Bas-Congo, l'écrit se résumait à la Bible et que celle-ci ne pouvait être conçue que sur le modèle des «fétiches» minkisi. Le mouvement kimbanǵuiste n'a pourtant rien d'un prophétisme «de contact», c'està-dire issu d'un contact superficiel avec le monde occidental. Il naît au contraire dans une société où le christianisme est présent depuis la fin du Xve siècle et où l'écrit circule également de longúe date, une société colonisée depuis plusieurs décennies et où les Européens sont des figures familières, qu'il s'agisse des missionnaires ou des «Blanes de l'État» (mindele ya leta). Cet article étudie ainsi la confrontation entre un prophétisme africain, l'administration coloniale et les missions chrétiennes à travers le prisme de l'écrit. S'inspirant librement des analyses de Max Weber (2014) sur le charisme et la bureaucratie, il examine comment le document écrit participe à la construction de l'autorité à la croisée des sphères politique et religieuse ${ }^{6}$.

\section{DU PROPHÉTISME AU MESSIANISME}

Au début de l'année 1921, la nouvelle se répand comme une traînée de poudre qu'un prophète est apparu au Bas-Congo et qu'il accomplit des miracles ${ }^{7}$. Cela faisait déjà quelque temps que Simon Kimbanǵu se sentait appelé à accomplir le travail de Dieu. Membre de la mission baptiste anǵlaise, il avait voulu devenir catéchiste, mais n'avait pas été officiellement reconnu comme tel par les autorités missionnaires ${ }^{8}$. Une nuit, en rêve, un étranger lui montre la Bible et lui déclare: «C'est un bon livre, tu dois l'étudier et prêcher.» Il tente de résister à cet appel, mais les rêves persistent et il finit par céder. Il se met alors à guérir les malades et les infirmes au nom du Christ. On dit même qu'il ressuscite les morts. Il exhorte son auditoire à renoncer à la polyǵamie et aux «fétiches », lui fait la lecture de la Bible et parle avec ferveur du salut. Il est souvent pris de violents tremblements ${ }^{9}$, signe de l'inspiration par l'Esprit (Mpeve). Dans ces moments-là, il arrive qu'il se mette à parler en «lanǵue du Ciel » (ndinga zulu), glossolalie incompréhensible. Le succès de Kimbangu est fulgurant: des milliers de personnes affluent vers son village, parfois depuis le Congo français ou l'Angola. Il est considéré comme un nǵunza, terme qui désigne un "prophète» dans la traduction baptiste de la Bible en kikongo. Dans les semaines et les mois qui suivent, d'autres ngunza apparaissent un peu partout au Bas-Congo et se mettent à «trembler» comme Kimbangu. Pour cette raison, les Européens désignent souvent le mouvement prophétique sous le terme de «ngounzisme».

Cette effervescence inquiète les autorités belges, promptes à voir une menace de subversion dans la moindre agitation. Elles cherchent à appréhender Kimbangu, qui parvient à leur échapper une première fois, mais qui, tel le Christ, se laisse arrêter sans résistance quelques mois plus tard. Condamné à mort en octobre 1921, il voit sa peine commuée en détention à perpétuité. Incarcéré à la prison d'Élisabethville, à l'autre bout du pays, il y restera jusqu'à sa mort en 1951, sans quasiment plus jamais avoir de contact avec le monde extérieur. Cela ne met cependant pas un terme au mouvement prophétique. Des disciples se réclament de lui et de nouveaux prophètes apparaissent régulièrement. Le kimbanguisme s'enracine dans toute l'aire kongo, touchant aussi bien les centres urbains que le monde rural, se jouant des frontières entre les colonies belǵe, française et portugaise.

Les autorités répriment sévèrement le mouvement, spécialement au Congo belge : interdiction officielle obligeant les adeptes à passer dans la clandestinité, régime d'occupation militaire dans les régions les plus touchées, milliers d'arrestations et de relégations dans des camps à l'intérieur du pays. Le gouvernement a fortement exagéré la menace que représentait le kimbanguisme, en croyant y voir une contestation de l'ordre colonial, alors que le message de Kimbangu se plaçait avant tout sur le terrain religieux. Mais c'est paradoxalement la répression qui contribue à politiser le mouvement et à lui donner un tour anticolonial, notamment à partir des années 1930. Les adeptes se montrent hostiles envers les agents du gouvernement, mais aussi envers les missionnaires, accusés d'avoir trahi Kimbangu. Les «chefs médaillés», auxiliaires indigènes de l'Administration, ne sont pas mieux considérés. Des cantiques kimbanguistes affirment par exemple: «Nous ne voulons plus de chefs, nous ne voulons plus de Blancs.» Ou encore: «Nous sommes Noirs, mais nous deviendrons Blanes. Les Blancs deviendront Noirs et nous serons les maîtres. » Les adeptes revendiquent parfois être des «Blanes noirs» (mindele ndombe), expression qui désigne les «évolués». L'opposition aux Européens relève avant tout de la contestation verbale, mais ne se traduit pas par une rébellion violente: le registre n'est pas celui de l'action, mais celui de l'attente. Le renversement de l'ordre colonial est placé dans un horizon eschatologique: les adeptes attendent la fin des temps qui marquera le départ des Européens.

L'absence de Kimbanǵu l'élève à un nouveau statut. En 1921, il se réclamait du Christ; après son arrestation, ses adeptes et les autres prophètes se réclament désormais de lui. Les rumeurs sur son compte annoncent qu'il est mort et ressuscité. Le prophète devient un messie, Mvulusi en kikongo, le Sauveur dont on guette le retour pour qu'il délivre les Noirs du jouǵ colonial et de tous leurs malheurs. On le présente également comme
5. Sur le rôle des documents dans la bureaucratie d'État, voir: Hull 2012.

6. Pour ce travail ont été consultées les archives administratives du Congo belge et du Congo français, ainsi que celles de plusieurs congrégations missionnaires.

7. Sur Kimbangu d'après les sources coloniales, voir: Vellut 2005; 2010.

8. Suppléant un clergé européen trop peu nombreux les catéchistes indigènes sont chargés d'évangéliser les villages éloignés des missions. Bien que l'historiographie kimbanguiste officielle affirme que Kimbangu était catéchiste, les archives de la mission baptiste semblent indiquer le contraire (Vellut 2010:170).

9. Sur l'importance du «tremblement» dans la gestualité religieuse au Bas-Congo, voir: Covington-Ward 2016. 


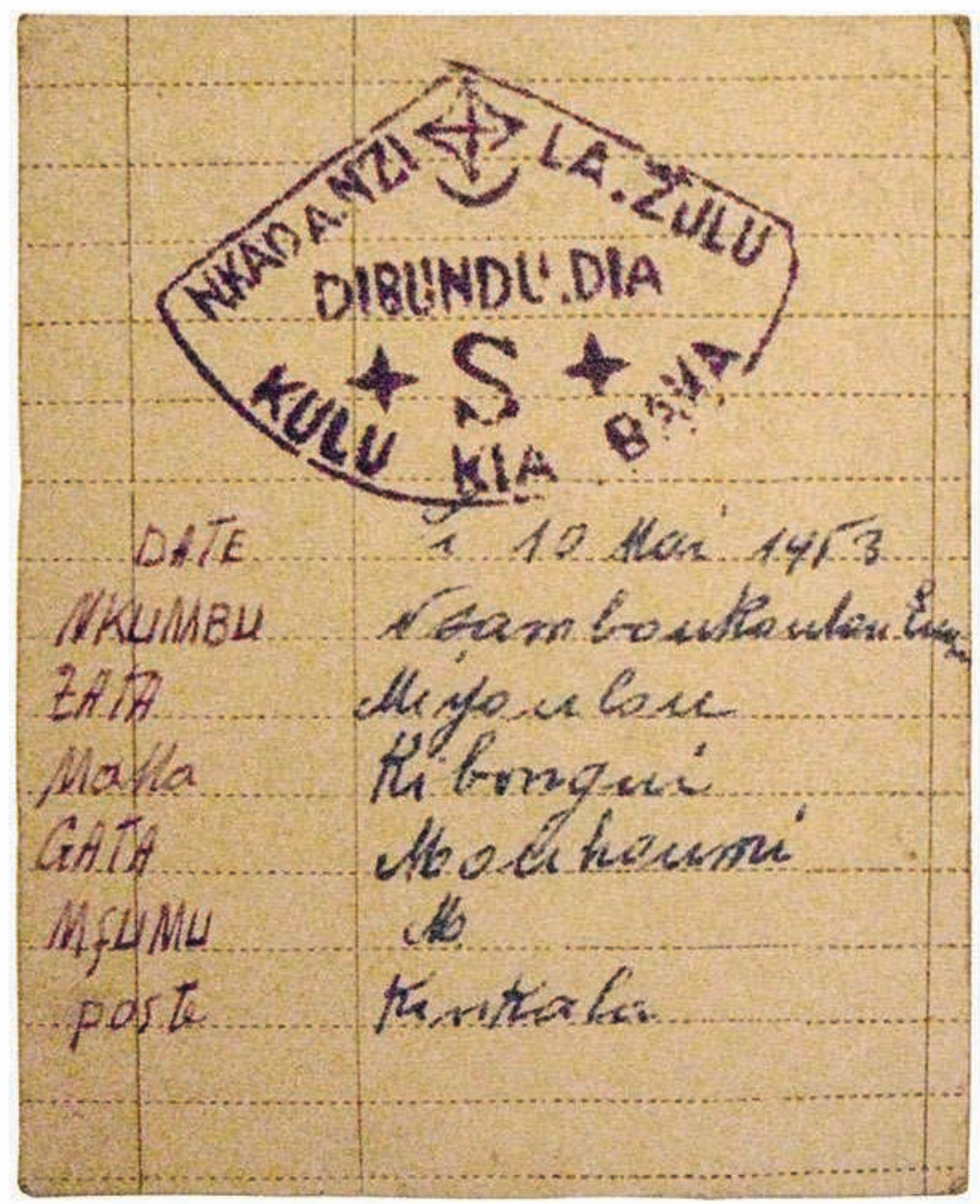

fig. 1

Passeport pour le Ciel, 1953. Fonds du Gouvernement général du Congo belge. Droits réservés.

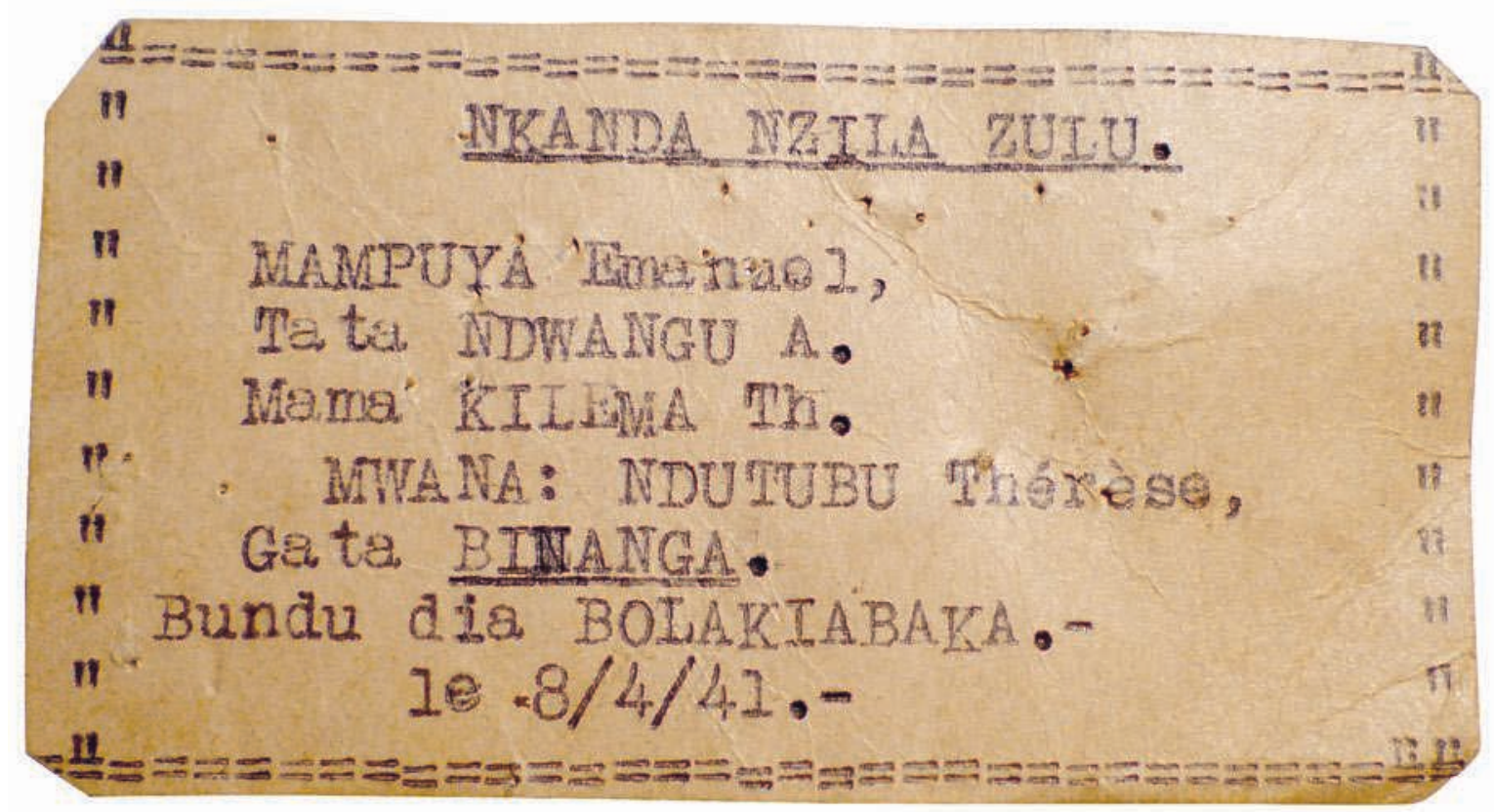




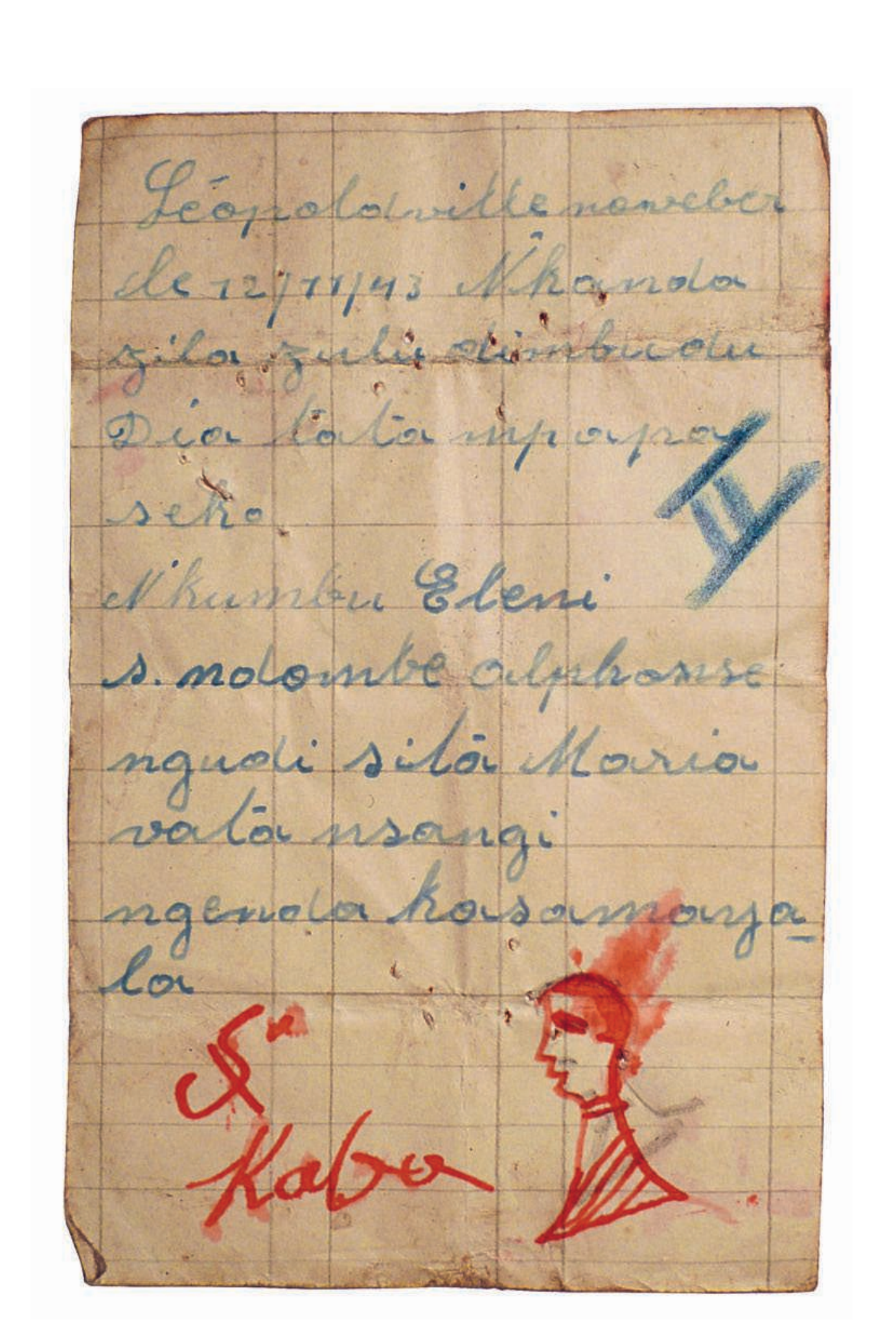


10. Pour une lecture politique des prophétismes congolais, voir également: Sinda 1974.

11. Fonds du Gouv. Gal du Congo belge (GG17706)

12. Fonds du Gouv. $G^{\text {al }}$ de I'AEF (5D64).

13. Fonds du Gouv. $G^{a}$ du Congo belge (GG7173) le «Roi du Congo » en lui donnant le titre de Ntinu, le souverain de l'ancien royaume kongo, ou de Mfumu, terme qui désiǵne un chef, mais aussi le Seigneur dans la Bible en kikongo. Cette réactivation de la figure monarchique dans un cadre anticolonial faisait dire à Balandier que le kimbanguisme représentait un «nationalisme sacré» $(1958: 94)^{10}$. Le prophétisme thaumaturgíque des années 1920 cède ainsi la place à un messianisme politique.

À la fin des années 1930, Simon Mpadi est un acteur-clé de ce nouveau messianisme. Catéchiste de la mission baptiste américaine, il rompt avec elle pour rejoindre l'Armée du salut, récemment implantée au Bas-Conǵo, où elle rencontre un succès fulgurant. Échappant au contrôle du clergé européen, la congrégation est détournée au service des intérêts indigènes. Ce «salutisme indigène» devient un mouvement anti-sorcellerie: s'enrôler dans l'Armée du salut ou serrer la main d'un salutiste permet de se disculper des accusations de sorcellerie et d'être purifié. Il sert également de paravent aux kimbanguistes condamnés à la clandestinité. Ce détournement repose sur un «malentendu productif»: le $\mathrm{S}$ brodé sur l'uniforme salutiste serait en réalité l'initiale du prénom de Kimbanguu. Nommé lieutenant de l'Armée du salut, Mpadi quitte la congrégation en 1939 pour fonder sa propre Éǵlise : la Mission des Noirs. Celle-ci est immédiatement interdite et Mpadi, qui se présente comme le successeur de Kimbangu et prône des positions séparatistes et anticoloniales, est arrêté. Pendant toute la durée de la Seconde Guerre mondiale, il est en cavale et s'évade à plusieurs reprises. Il est finalement repris en 1945 et emprisonné à Élisabethville, où il demeurera jusqu'à l'indépendance du pays en 1960.

Mpadi réussit à faire des émules et à implanter des églises locales dans tout le Bas-Congoo, mais aussi au Congo français et en Angola, où il se réfugie quelque temps. En AEF, il opère la jonction entre les partisans de Kimbangu et ceux de Matsoua, le fondateur du mouvement amicaliste qui militait pour les droits des Congolais, mort en prison en 1942. Parmi les Lari, un véritable culte prend forme autour du leader politique transfiguré en messie après sa disparition. Kimbanguisme et matsouanisme se sont fécondés mutuellement: le premier est parti du terrain religieux pour rejoindre le terrain politique; le second a suivi une trajectoire inverse.

Les membres de la Mission des Noirs se distinguent par leur uniforme kaki: on parle ainsi de «l'Église kaki» ou du «kakisme». Malǵré les ambitions de Mpadi, le mouvement kakiste n'est pas vraiment unifié, mais forme une constellation de chapelles ou de cellules locales plus ou moins indépendantes. À leur tête se trouvent des prophètes comme Mavonda Ntangu, qui dirige le mouvement au Congo français, ou encore Bola-Mananga, qui prétend être la réincarnation de Kimbangu et fonde des cellules à Boma et à Léopoldville. Tous ces groupes partagent un certain air de famille. Ils se reconnaissent à leur goût pour les uniformes, les galons et les grades, inspiré de l'Armée du salut et de sa hiérarchie quasi militaire; à l'importance accordée aux drapeaux (un autre héritage salutiste), source de pouvoir spirituel; à tout un attirail d'objets rituels, bâtons appelés «ma-canon» servant à combattre les sorciers, baǵues pour communiquer avec les morts ou entrer en contact avec l'Esprit, cannes faisant office d'insignes de pouvoir; et enfin, à une production conséquente de documents écrits, parmi lesquels les passeports pour le Ciel.

\section{ÉGRITURE ET BUREAUCRATIE}

Dans les archives coloniales, les passeports pour le Ciel sont répertoriés sous divers autres noms : « cartes », « certificats », «attestations », «tickets », «bulletins», «laissez-passer». En 1943, par exemple, les autorités découvrent une mallette lors d'une perquisition au sein de la cellule dite du Pasteur, un petit groupe actif à la frontière belgo-française. Elle contient l'attirail habituel des kakistes: des uniformes, des drapeaux, une canne, des bâtonnets, des bagues, une bible, des hymnaires, divers manuscrits, quelques papiers avec des «dessins ǵrossiers », ainsi qu' "un paquet de cartes du Saint-Esprit dessinées par un indigène ${ }^{11}$ ». En 1948, dans le district de Boko, les autorités françaises arrêtent le meneur d'une cellule «à tendance fétichiste antieuropéenne». Quantité d'objets sont saisis chez lui :

Il s'agit de bâtons liturgiques, de bouchons de bois, d'une soutane de pasteur avec insignes, de treize galons kakistes, de bonnets de pasteur, de cing boubous avec insignes, de mouchoirs kakistes et de drapeaux kakistes, de livres de cantiques, de douze laissez-passer accompagnés d'une liste de donateurs ${ }^{12}$.

En 1952, un officier de police surprend une réunion kimbanǵuiste à Léopoldville :

Les attestations d'adhésion à la secte nkanda nzila zulu étaient toutes déposées sur la table qui se trouvait au milieu de la case. Celle-ci était éclairée par des cierges. Un drapeau aux insignes kimbanguistes avait été déposé par terre. Sur le drapeau avait été mis la Bible. Sur cette Bible étaient déposés d'autres nkanda nzila zulu, ainsi qu'un bâton appelé nkawa. Dans la place à côté était pendue une longue soutane blanche, ornement des pasteurs de la secte ${ }^{13}$.

Il s'agissait probablement d'un rituel d'intronisation de nouveaux membres. Les passeports pour le Ciel font en effet office de certificats d'adhésion et sont d'ailleurs parfois appelés kalati za dibundu, «cartes d'éǵlise ». Ils sont habituellement délivrés au nouvel adepte après son baptême. Ces documents de type administratif témoignent du processus d'institutionnalisation du prophétisme. L'organisation de la Mission des Noirs en est la meilleure illustration. Les rapports officiels la décrivent comme une «secte hiérarchisée prophétique» et précisent qu' «elle compte de très 


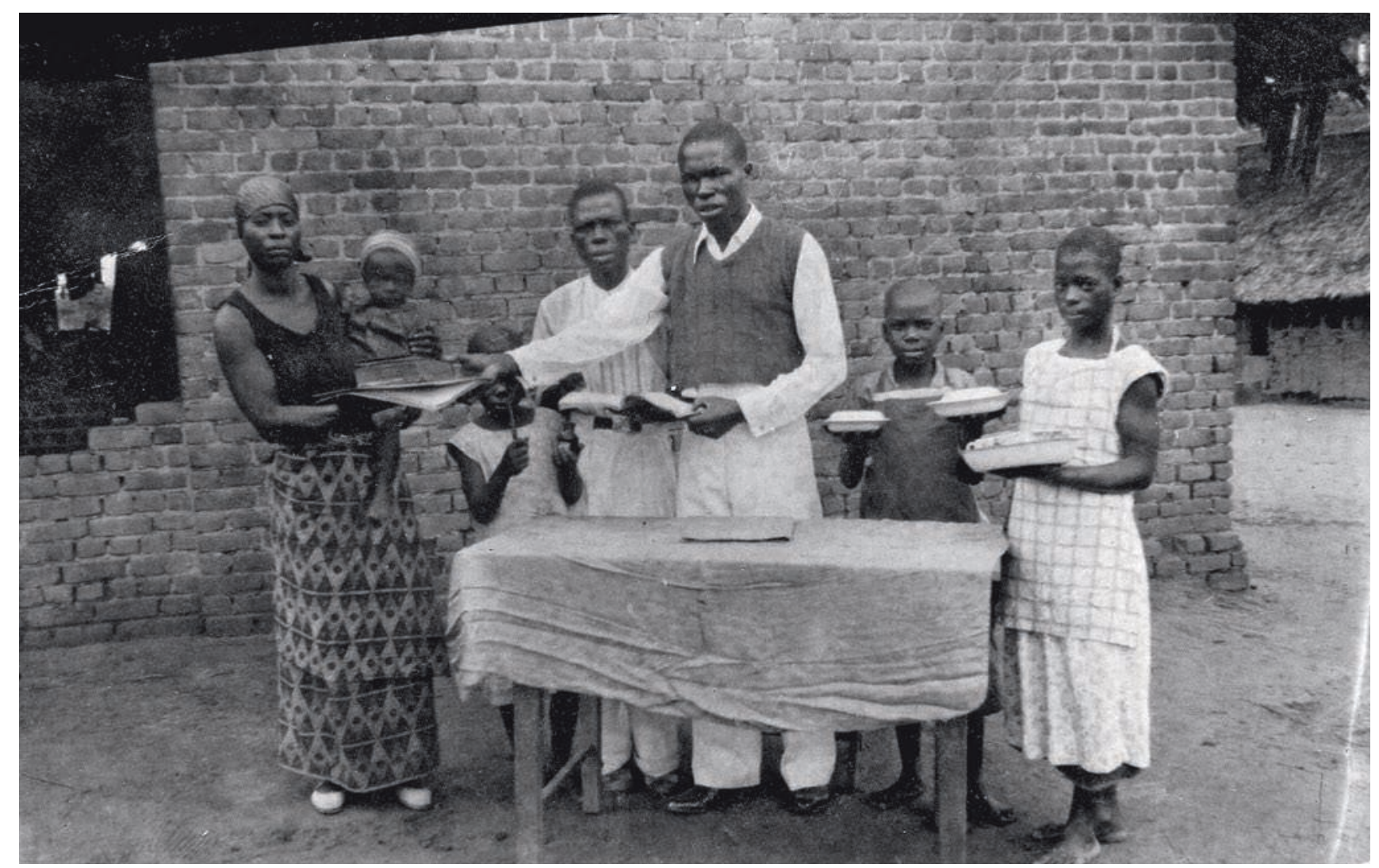

fig. 4

Photographie de Simon Mpadi, années 1940. Fonds du Gouvernement général du Congo belge. Droits réservés.

nombreux meneurs et adeptes rationnellement orǵanisés en diverses équipes dites "éǵlises" 14 ». Mpadi se décerne le titre de «chef des apôtres» et décide de se rebaptiser Simon-Pierre, l'ajout du second prénom soulignant son statut de fondateur d'Éǵlise. À la tête de la Mission des Noirs, il est assisté de douze ǵrands apôtres qui supervisent cent vingt apôtres régionaux en charǵe des églises locales, eux-mêmes responsables de trois cents apôtres villageois. S'y adjoignent des groupes de sept chargés du recrutement et de la police sous la direction d'un huitième individu, nommé «capita», terme désignant un contremaître dans le vocabulaire colonial belge. Chacun de ces grades possède un uniforme distinctif. Même si cette belle organisation avec son arithmétique impeccable n'est qu'un organigramme de papier, elle atteste de l'importance du modèle bureaucratique au sein de la Mission des Noirs.

Mpadi incarne bien la figure du prophète bureaucrate qui administre son Éǵlise à travers un flux continu d'écrits. Quelque temps avant de fonder la Mission des Noirs, il dit avoir eu une vision annonciatrice: il rencontre plusieurs personnages bibliques qui lui remettent un uniforme kaki, un livre pour recenser les fidèles, ainsi qu'un bâton de commandement comparé à celui de Moïse. Le Livre révélé est un thème classique de l'autobiographie des prophètes issus du christianisme, au Congo comme ailleurs. Dans la vision de Mpadi, ce livre n'est cependant pas une bible, comme c'est généralement le cas, mais un registre administratif.
La Mission des Noirs dispose en outre d'un règlement, un genre au croisement de l'écrit administratif et de l'écrit doctrinal, également très prisé par Mpadi. Ce dernier y a fixé de manière tatillonne la liturǵie de l'Église, mais aussi les moindres détails de la vie des adeptes, l'habillement, les repas, l'hygiè̀ne, la sexualité et même le mobilier domestique.

Les nouvelles recrues ont obligation d'apprendre ce règlement sous la supervision d'un formateur. Cette manie réǵlementaire reproduit jusqu'à l'excès la discipline des corps imposée par l'ordre colonial, en particulier dans l'armée et les missions. Comme le prouve cet exemple, l'écrit bureaucratique joue un rôle de premier plan dans l'exercice de l'autorité hiérarchique à l'intérieur de l'Église.

Parmi les documents diffusés dans la Mission des Noirs, on trouve des photographies montrant Mpadi et ses proches se mettant en scène dans des tableaux allégoriques. Il faisait reproduire ces images en plusieurs exemplaires et les envoyait aux différentes églises sous son contrôle, accompaǵnées de légendes explicatives. Sur l'une d'elles, Mpadi est debout derrière la «table du chef des apôtres », sur laquelle est posé un cahier; un enfant lui présente un encrier et un porte-plume pour qu'il puisse «écrire les règlements pour les expédier aux églises des apôtres »; à ses côtés, son secrétaire «avec le livre des rèǵlements pour demander des renseignements », et la femme de Mpadi qui lui tend un autre livre, ainsi qu'une bible ${ }^{15}$ (fig. 4). Comme le montre ce tableau photographique, le travail administratif est traité avec beaucoup de solennité dans l'Église, donnant lieu à un véritable ritualisme bureaucratique.
14. Fonds du Gouv. $G^{\text {al }}$ du Congo belge (GG16255)

15. Fonds du Gouv. $G^{\text {al }}$ du Congo belge (GG18305) 
16. Fonds des Affaires indigènes du Congo belge (Al(4738) II.Q.3.C).

17. Fonds du Gouv. Gal du Congo belge (GG16255)

18. Fonds du Gouv. $G^{\text {a }}$ du Congo belge (GG50973)

19. Sur glossolalies et pseudo-écritures, voir: Déléage 2018.

20. Fonds du Gouv. $G^{a}$ du Congo belge (GG5858).

21. Elle peut aussi passer par la lecture (ou plutôt son simulacre): les prophètes regardent le ciel, la main tournée vers lui, puis ils «lisent» les révélations divines dans leur paume.

22. Fonds du Gouv. $G^{a}$ du Congo belge (GG5970).
Dans chacun des lieux fréquentés par Mpadi, les autorités découvrent des paquets de documents. Il parvient encore à écrire et diriger son Éǵlise lorsqu'il est relégué ou emprisonné : grâce à «des amis qui lui procurent du papier et de l'encre, il a à sa disposition des écrivains, expédie ses correspondances par

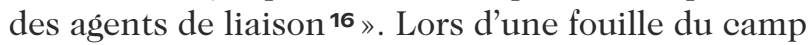
de Befale où il est interné, les surveillants saisissent une lettre de lui destinée à un autre apôtre:

Je ne veux pas envoyer de nouvelles par la poste. Faites venir toutes les lettres par les mains. Je vais écrire à toutes les églises. Avertissez à Kinshasa qu'à partir du 26, ils doivent attendre Albert Kinzonzi au Beach. Je vous ai écrit beaucoup de lettres dans lesquelles les préceptes ont été tapés à la machine. Quand la collecte sera faite dans les églises, on achètera d'autres lettres et on tapera les préceptes à la machine. Un autre grand écrivain, Minzeki Michel, a commencé à écrire à la machine. Nous avons des frères à Basankusu. Quand vous aurez fini d'écrire les préceptes, il faudrait leur envoyer sept copies. Vous ferez autant de copies qu'il y a d'églises là-bas ${ }^{17}$.

Quelques mois plus tard, alors que de nouveaux documents ont été trouvés sur lui, Mpadi répond avec aplomb lors de son interrogatoire: "Aussi longtemps que ces papiers existent, on en fera des copies et le mouvement continuera ${ }^{18}$ ! 》 Messagers, secrétaires, machines à écrire, copies carbone, tout cela trahit un souci pointilleux du travail administratif. Parmi l'abondante production écrite de Mpadi, on trouve quantité de documents bureaucratiques, notamment des cahiers recensant les membres de la Mission des Noirs, éǵlise par éǵlise. Ces regiistres comptent des milliers de noms: chaque entrée, dûment numérotée, précise sur plusieurs colonnes l'identité de l'adepte, le nom de ses parents, son village, le secteur administratif dont il dépend, son grade dans l'Éǵlise, et même s'il sait écrire ou non (fiǵ. 5).

On trouve également des livres de compte, des reçus de cotisations et des tampons officiels. En 1944, les autorités découvrent quatre cachets et une boîte de cirage portant l'inscription «tampon»: chaque cachet comporte le nom d'un apôtre, son numéro dans l'organiǵramme de l'Éǵlise et le nom de la chapelle qu'il dirige (fig. 6). La Mission des Noirs produit même des actes officiels: nomination d'apôtres, actes de mariage ou actes judiciaires, signés par Mpadi ou l'un de ses secrétaires, mais rédigés "au nom du Sauveur Simon Kimbanǵu». Ces écrits performatifs accomplissent une action (introniser, marier, prononcer un verdict) au nom d'une autorité : celle de Kimbanǵu. Selon la typologiie des actes de lanǵage d'Austin (1962), ce sont des «exercitifs». Cela montre que la Mission des Noirs ambitionne de se substituer à l'administration coloniale, ce qui inquiète au plus haut point les autorités belges, qui jugent que l'Éǵlise constitue «le plus dangereux des mouvements politico-religieux» :
En quelques semaines furent balayés tout ensemble les fondements de la société indigène et nos réglementations européennes: plus de chefs, plus de tribunal, plus d'état civil. Le dignitaire mpadiste fut tout à la fois chef, juge, officier d'état civil, gardien de prison, trésorier, médecin et même dépositaire des valeurs dotales et intermédiaire matrimonial.

(Ryckmans 1995: 283)

La plupart des cellules kakistes ont produit des écrits du même type que ceux de la Mission des Noirs. Les passeports pour le Ciel - certificats servant à valider l'adhésion des nouveaux membres - sont à mettre sur le même plan que les registres de recensement ou les actes officiels de Mpadi. Dans les années 1940, on assiste ainsi à la naissance de petites Églises indépendantes dotées d'une organisation formelle. Ce processus s'accompagne d'une certaine routinisation du charisme: le prophète thaumaturǵe s'efface derrière le prophète bureaucrate. En réalité, charisme et bureaucratie ne sont pas antinomiques, mais peuvent aller de concert, comme l'a souliǵné Thomas Kirsch (2008) ou encore André Mary (2009). Les effusions de l'Esprit ne sont pas moins importantes parmi les kakistes des années 1940 que chez les ngunza des années 1920: on continue de «trembler» tout autant. Les glossolalies n'ont pas disparu non plus: Mpadi lui-même s'exprimait parfois en «langue du Ciel». Il arrive aussi que les prophètes inspirés par l'Esprit recourent à des "ǵlossographies», écritures indéchiffrables qui font pendant aux ǵlossolalies orales ${ }^{19}$. En 1951, dans la région de Madimba, les autorités s'inquiètent des menées d'un certain Jacob Boto, un ancien chef de secteur révoqué pour son implication dans le mouvement prophétique. Prétendant être mort et ressuscité, Boto passe ses journées à écouter son gramophone, il «tremble» et reçoit des messaǵes du Ciel, qu'il note par écrit «à l'envers au moyen de siǵnes mystérieux, comme l'alphabet morse ou arabe 20 ». La connexion avec le Ciel peut donc également passer par l'écrit ${ }^{21}$.

\section{LES CARTES DU CIEL}

Les passeports pour le Ciel servent à l'occasion de laissez-passer lors des réunions clandestines, le terme figurant parfois sur les certificats. Au sein d'une cellule kakiste, les autorités belges découvrent un document non daté intitulé «Congo laissez-passer ${ }^{22}$ ». Il s'aǵit d'une circulaire fixant le modèle des passeports et expliquant leur fonction. Au centre, un spécimen précise les informations à renseiǵner : le nom de l'adhérent, celui de ses parents, son village, la division administrative dont il dépend. Ce modèle-type est encadré par deux paraǵraphes:

J'ai juré pour la race des Noirs que tout homme, soit Blanc, soit Noir, qui arrêtera encore des prophètes, sachez bien que je lui ferai la guerre jusqu'au moment où Jésus-Christ viendra nous juger. Car, en 

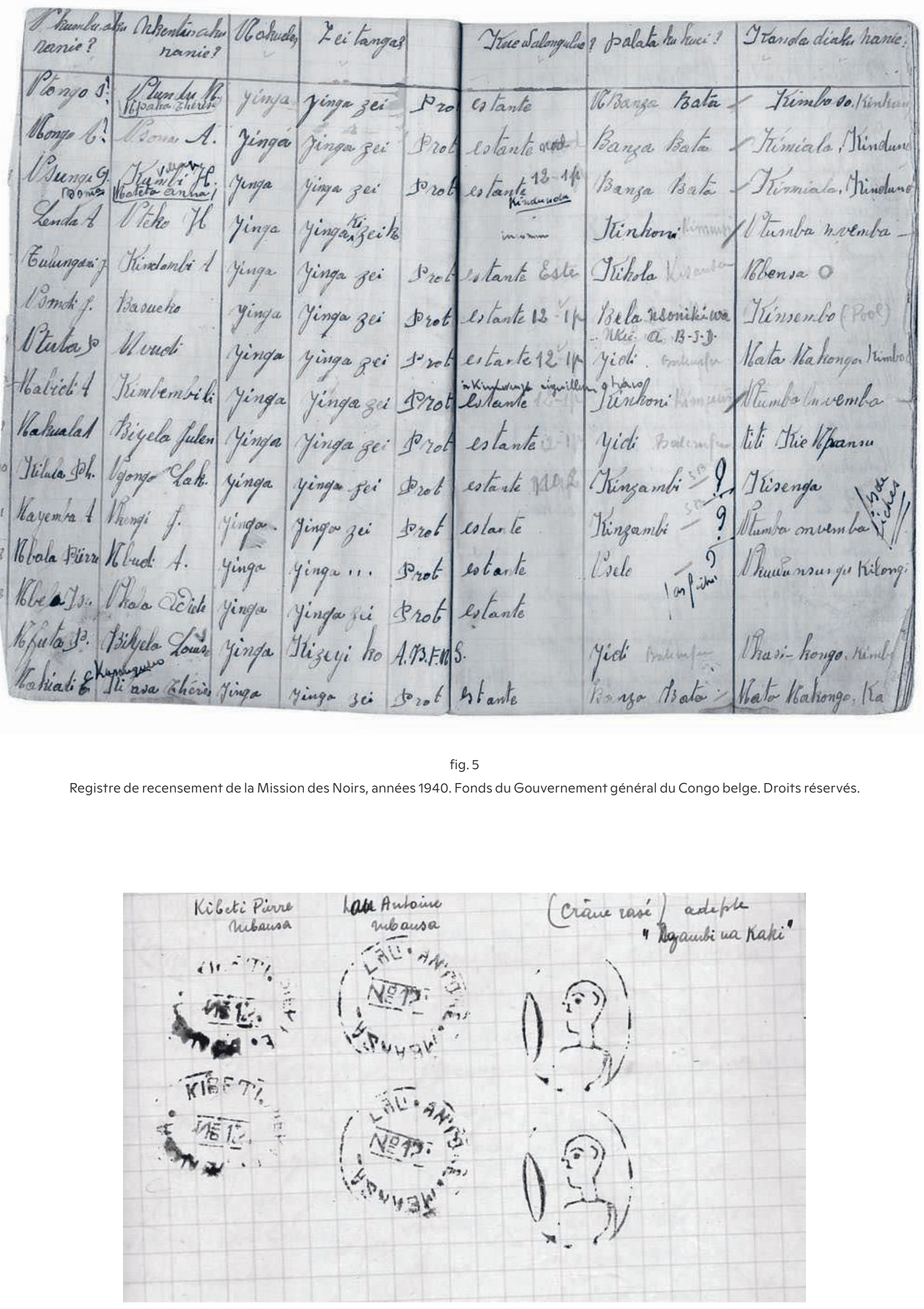




fig. 7

Carte du Ciel, années 1940, in Andersson 1958: planche 4. Droits réservés.

23. Missionnaire suédois présent entre 1929 et 1954 au Congo français, dans une station proche de la frontière belge, Andersson est l'un des meilleurs connaisseurs duprophétisme de cette période. Sur cette figure de l'ethnologie missionnaire, voir: Coyault 2019.

24. Épées, cannes et ombrelles sont des insignes du pouvoir qui remontent à l'époque

de la première évangélisation de la première evange
du royaume kongo

(le christianisme devenant religion officielle à la fin du xve siècle). vérité, la terre brûlera et les eaux trembleront. Les øuvres de chaque homme, le prophète les a écrites sur des papiers, toutes ces histoires sont inscrites dans un Congo laissez-passer en voyage. Toi, ne t'enfuis pas pour ne pas être pris, celui qui a reçu cette lettre ne doit pas avoir peur. Toi, le distributeur de ces papiers, vérifie bien qui doit les recevoir: les prophètes, les frères et les enfants aussi. Ce Dieu que tu dois adorer est BolaMananga Nzambi, le Roi Simon Kimbanǵu.

L'auteur de la circulaire, possiblement BolaMananga lui-même, justifie l'importance des laissezpasser en les inscrivant dans une perspective eschatologique: ces «papiers» serviront à juǵer leurs porteurs lors du Jugement dernier. Selon des informations recueillies par Efraim Andersson (1958: 162) auprès d'un ancien adepte, le document était placé entre les mains du défunt en guise de viatique ${ }^{23}$. Les passeports pour le Ciel ne sont donc pas de simples cartes de membres, mais sont littéralement conçus comme des laissez-passer pour entrer au paradis. Il faut les replacer dans le contexte des attentes millénaristes de l'époque: dans les années 1940, les adeptes imaǵinaient que la fin des temps était proche (ce qui n'est peut-être pas sans rapport avec les bouleversements de la Seconde Guerre mondiale).

Il existe en réalité deux formats de passeports pour le Ciel: l'un privilégie l'écrit; l'autre, le dessin.
Les passeports dessinés comportent peu de texte. L'identité du porteur n'est pas toujours mentionnée et, souvent, seul un titre figure en tête du document : kalite disiele, «carte du Ciel» en kikongo créolisé (ou parfois simplement kalite). Les passeports sont en revanche couverts de motifs en couleurs: des astres (étoiles, soleils, lunes); des véhicules (avions, camions, plus rarement un bateau); des insignes kakistes (drapeaux, cannes, bâtons, croix, épées, uniformes), mais aussi des ombrelles ou des fleurs; très peu de figures anthropomorphes, mais des oiseaux, parfois un poisson et de curieuses créatures qui font penser à des scolopendres ${ }^{24}$ (fig. 8). Ces passeports imaǵés proviennent des mêmes cercles kakistes que ceux écrits: les exemplaires reproduits dans l'ouvrage d'Andersson appartenaient par exemple à des adeptes du prophète Mavonda Ntanǵu. Dans la cellule du Pasteur, ils sont dessinés par «Lieutenant André», mais signnés par le pasteur lui-même en sa qualité de chef. Les nouvelles recrues reçoivent un passeport simplement décoré d'une croix, de deux étoiles et d'un drapeau. Ceux des dirigeants de la cellule sont plus élaborés :

Celui de Goma Simon comportait un couteau, une rosace, deux étoiles, le soleil, la lune (un croissant), un crucifix, un drapeau (couleurs rouge, blanc, noir), une chasuble, un pot defleurs, un poisson. Des bandes de couleurs rouge, jaune, noire se voyaient au milieu du certificat, 
puis un chariot sur lequel on voit un dessin représentant un homme et qui vaut la photo du détenteur du certificat. Son nom y figure également ainsi que son village, et ce certificat est signé Alasoboqwee Makazagulu A Tiki P. 43. [...] Les certificats de ces principaux membres sont homologués au verso par une formule grossièrement écrite à l'encre avec un morceau de bois et intraduisible. On y voit deux sceaux, faits au moyen d'un bout de bois rond, fendu ${ }^{25}$.

Ces imaǵes sont une représentation symbolique du Ciel. Elles sont orientées selon une liǵne de force verticale. Leur centre est occupé par un motif principal en forme de croix : étoile à quatre branches, croix latine ou pattée, avion. À rebours de nos conventions graphiques, les avions pointent généralement vers le ciel. De manière encore plus inattendue, les camions sont parfois orientés de la même façon. Autour du sujet central, des motifs secondaires accentuent encore la verticalité de l'image: bâtons, épées, hampes des drapeaux et des ombrelles. La figure centrale cruciforme symbolise la connexion entre l'ici-bas et l'au-delà, conformément à la cosmologie kongo (MacGaffey 1986). Comme Cécile Fromont (2011) l'a montré, dans le royaume kongo, la croix est un symbole syncrétique qui associe des éléments chrétiens et des représentations autochtones concernant les relations entre le monde des vivants et celui des morts. Les avions dessinés sur les passeports (et dans une moindre mesure les camions) possèdent la même fonction eschatologique que les croix : ils permettent d'accomplir le voyage jusqu'au Ciel et done de relier les deux mondes. Ce n'est pas un hasard qu'il s'agisse de véhicules associés aux Blancs, eux-mêmes souvent identifiés aux morts. L'un des exemplaires reproduits par Andersson fusionne le motif de l'avion et celui de la croix latine: il figure un avion en train de monter vers le ciel au milieu des étoiles, avec un passager dans le cockpit surmonté d'un drapeau (fig. 7).

Selon le témoignage d'un ancien adepte, les motifs dessinés sur les passeports représenteraient les «siǵnes» (bidimbu) des «gens du Ciel» (bisi sulu). En reconnaissant leurs emblèmes, ceux-ci laisseraient alors passer le porteur du document. L'exemplaire avec l'avion-croix est d'ailleurs intitulé kalite disiele voi libres, "carte du Ciel voie libre». Ces cartes sont donc censées pouvoir accomplir ce qu'elles décrivent en imaǵes : elles sont une représentation du Ciel, en même temps qu'un laissez-passer pour y entrer. Qu'ils soient dessinés ou écrits, les passeports pour le Ciel prétendent ainsi à une certaine forme de performativité. Celle-ci n'est cependant que virtuelle, car elle est prise dans l'horizon d'attente propre au messianisme: c'est seulement à la fin des temps, lors du retour du Messie, que les documents pourront accomplir leur promesse. Mais ce type de performativité différée est en réalité caractéristique de l'écrit, en raison de la disjonction entre les actes d'écriture et de lecture (Fraenkel 2006).

\section{LE VOYAGE DU PÈLERIN AU CONGO}

La métaphore du «passeport pour le Ciel» n'est pas née au Congo: elle est employée au moins depuis la fin du $\mathrm{XVI}^{\mathrm{e}}$ siècle dans le christianisme européen, où elle sert à évoquer la valeur eschatologique des sacrements, spécialement ceux donnés en viatique aux mourants. Dans le sillage de la Réforme, elle se trouve prise dans les débats qui traversent le monde chrétien au sujet du salut, de l'autorité de l'Église et de l'efficacité de ses rites. Au XIX siècle, il s'agit d'une image d'usage courant dans les milieux baptistes et évangéliques ${ }^{26}$. Elle se diffuse ensuite plus largement par le biais des missions. En Jamaïque, des pasteurs baptistes distribuaient aux esclaves convertis des certificats attestant qu'ils étaient prêts à accomplir certains rituels (Hofmeyr 2004: 91); ces documents étaient appelés des passeports pour le Ciel et leurs détenteurs étaient parfois enterrés avec eux. C'est vraisemblablement par le même truchement que la métaphore a voyagé jusqu'au Bas-Conǵo, où elle a pu frapper l'imaǵination des fidèles des missions protestantes, principal lieu d'incubation du mouvement prophétique.

Après une première période d'évangélisation entre la fin du Xve et le début du XIX siècle, le Bas-Congo connaît à partir des années 1880 une seconde vague missionnaire, contemporaine de la colonisation du pays. La mission baptiste anglaise est la première à s'installer dans la région. La mission baptiste américaine et la mission évangélique suédoise suivront plus tard. Du côté des congrégations catholiques, on trouve des jésuites, des scheutistes, des rédemptoristes, ainsi que des spiritains en territoire français. Il existe une vive concurrence - et parfois de l'hostilité - entre catholiques et protestants. Alors que les premiers se montrent proches des intérêts de l'État, les seconds sont perçus comme des étrangers et leurs rapports avec l'Administration sont parfois tendus.

Les protestants privilégient l'évangélisation en langue vernaculaire. Cela suppose de prêter une attention particulière à la langue: les missionnaires publient des grammaires et des dictionnaires et traduisent la Bible en kikongo ${ }^{27}$. Une bonne partie du vocabulaire kimbanguiste provient d'ailleurs de ces traductions, le terme ngunza au premier chef. Les protestants mettent l'accent sur le rapport personnel aux Écritures, là où les catholiques privilégient le catéchisme oral. Leur programme d'éducation insiste par conséquent sur la maîtrise de la lecture et de l'écriture en kikongo ${ }^{28}$. Cela suscite une forte demande pour l'écrit imprimé, supérieure au tiraǵe des presses locales, majoritairement entre les mains des protestants (Yates 1987). La production d'écrits par les Congolais est également valorisée: les catéchistes publient dans les périodiques des missions et se révèlent de prolifiques auteurs d'hymnes, un genre littéraire très important dans le protestantisme évangélique et fort prisé au Congo.

Même si la masse des adeptes se recrute aussi parmi les catholiques et les «païens», les principaux acteurs du prophétisme sont issus du protestantisme, à l'imaǵe de Kimbangu, Mpadi et Mavonda Ntanguu,
25. Fonds du Gouv. Gal du Congo belge (GG17706).

26. De nos jours, dans les cercles évangéliques nord-américains, les fidèles peuvent acheter des «passports to Heaven»: calqués sur les passeports nationaux, mais établis au nom du Christ, ils permettent de devenir «citoyen du royaume des Cieux».

27. Des dictionnaires et des catéchismes en kikongo ont été publiés dès les $x v l^{e}-x v I I^{e}$ siècles par les jésuites et les capucins envoyés au royaume kongo, mais aucune traduction de la Bible. De manière plus générale, sur la dimension linguistique de l'entreprise missionnaire, voir: Hanks 2010.

28. Dans la première moitié du $x x^{e}$ siècle, le Congo belge possède l'un des taux d'alphabétisation les plus élevés du continent. 
29. Sur ce livre et sa diffusion missionnaire, voir: Hofmeyr 2004

30. Depuis le $x v I^{e}$ siècle le terme $n k a n d a$, qui signifiait à l'origine «peau, écorce, étoffe», sertégalement à désigner le papier et, par extension, tout type d'écrit: un livre, une lettre, un document administratif ou la Bible (Brinkman et Bostoen 2018) respectivement d'anciens membres des missions anglaise, américaine et suédoise. Beaucoup sont des catéchistes en rupture de ban. Ils appartiennent à une petite classe éduquée, très imprégnée de culture chrétienne, mais frustrée que son instruction ne lui ait pas permis d'accéder à la réussite sociale qu'elle espérait: c'est souvent le refus d'une promotion ou d'une reconnaissance officielle qui entraîne la rupture avec la mission et suscite la vocation prophétique. En somme, les missionnaires étaient venus annoncer une «Bonne Nouvelle» dont les promesses tardaient trop à se réaliser. Cette affinité du prophétisme avec le protestantisme et son rapport particulier à l'écrit est confirmée par les kimbanguistes, qui professent n'avoir plus besoin des missionnaires depuis qu'ils ont appris à lire la Bible par eux-mêmes. Catholiques et administrateurs dressent le même constat, mais sur un ton accusateur: ils reprochent aux protestants d'avoir engendré le prophétisme, tel un monstre couvé en leur sein, puis de l'avoir laissé prospérer, voire encouragé. Le père Jaffré, un spiritain, affirmait ainsi que «le kimbanguisme au Congo belge, puis le ngounzisme au Conǵo français sont nés du libre examen protestant» (1934: 660). Il est vrai que, notamment au début, une partie des missionnaires protestants entretenaient une certaine ambivalence vis-à-vis de ce réveil religieux ayant conduit des milliers de "païens» à vouloir embrasser la foi chrétienne.

La prédication de Kimbangu au cours de l'année 1921 déclenche une ruée sur les bibles et les livres de cantiques. Les adeptes sélectionnent les chants qui leur conviennent, notamment ceux évoquant le thème du salut ou du combat. Puis ils se mettent à produire leurs propres hymnes, décalquant parfois un texte original en remplaçant le Christ par Kimbangu Certains cantiques, appelés «chants du Ciel» (nkunga mya zulu), sont directement inspirés par l'Esprit. À côté de la Bible et des hymnaires, un autre ouvrage reliǵieux a joué un rôle important dans le prophétisme: Le Voyage du pèlerin (The Pilgrim's Progress) de John Bunyan 29. Publié en 1678, ce récit allégorique raconte les tribulations de Christian - «chrétien» en anglais - sur le chemin de la Cité céleste. L'écrit y occupe une place centrale. Au début du récit, Christian est en train de lire la Bible (simplement désignée comme «un livre») et il la garde à la main pendant tout son périple. Il est aussi question d'un autre genre de document: dans un épisode, trois anges lui remettent un "parchemin avec un sceau», également décrit comme un «laissez-passer» ou un «certificat» ailleurs dans le récit. Lorsqu'il parvient aux portes de la Jérusalem céleste, il doit présenter ce document aux anges qui en gardent l'entrée pour qu'ils l'autorisent à passer. Juste après lui, Iǵnorance ne peut produire de laissez-passer et il est chassé par une porte latérale qui mène en enfer.

L'ouvrage de Bunyan est un classique du protestantisme évangélique. Traduit dans plus de deux cents langues, dont pas moins de quatre-vingts pour l'Afrique, c'est un best-seller missionnaire. La première traduction en kikongo est publiée en 1897 par la mission baptiste anglaise. Le Voyage du pèlerin fait office de manuel d'évangélisation au sein des missions protes- tantes, d'autant que son caractère allégorique fait écho à certains genres de la littérature orale des Bakonǵo, comme les contes et les proverbes. Les illustrations de l'ouvrage sont utilisées à des fins d'édification, après avoir été adaptées au contexte local: les protagonistes du récit sont représentés sous les traits d'Africains.

Dans certaines éditions, les gravures sont remplacées par des photographies mettant en scène des catéchistes indigènes en train de mimer les principaux épisodes du voyage de Christian (fig. 9). Également déclinées sur d'autres supports (cartes postales, affiches, plaques peintes pour lanterne magique), ces imaǵes étaient largement diffusées au Bas-Congo.

Le récit allégorique de Bunyan a nourri l'imagination des Bakongo protestants et, partant, celle des adeptes du mouvement prophétique. On en trouve d'ailleurs trace dans la biographie de Kimbangu: lorsque les autorités viennent l'arrêter, il parvient à s'échapper en emportant son hymnaire; dans sa fuite, il tombe à l'eau, mais le livre reste miraculeusement sec. Cet épisode évoque la scène au cours de laquelle Christian traverse le «Bourbier du Découragement» avec son livre à la main. L'ouvrage reste une référence importante dans le kakisme: en 1941, lors de l'arrestation d'un membre de la Mission des Noirs, les autorités en découvrent un exemplaire au milieu de bibles, d'hymnaires, de registres et d'uniformes. C'est même la principale source d'inspiration des passeports pour le Ciel. L'épisode où Christian présente son laissezpasser aux gardiens de la Cité céleste est d'ailleurs presque toujours illustré dans les éditions africaines.

Rappelons qu'en kikongo, "passeport pour le Ciel» se dit nkanda nzila zulu, "papier du chemin du Ciel». Or, Bunyan raconte justement le voyage d'un pèlerin sur le «chemin» (nzila) de la Cité céleste, le terme figurant au titre de l'ouvrage: Ngyend'a munduti a nzila. La Cité céleste est appelée Mbanza, la «Ville», mais on compte aussi plusieurs occurrences du mot zulu à propos du paradis. Enfin, le terme nkanda est celui utilisé pour désigner le laissez-passer de Christian (mais aussi sa bible) ${ }^{30}$. Dans un passage du récit, ce document est décrit comme un «parchemin avec un sceau», en kikongo nkanda wina ye dimbu, littéralement un «papier avec un signe». Or, comme nous l'avons vu, les dessins sur les passeports représentent précisément des «signnes» (bidimbu) que les «gens du Ciel» sont censés identifier pour laisser passer le porteur du document. Ces créatures, aussi appelées «plantons du Ciel» dans une cellule kakiste, sont manifestement calquées sur les gardiens de la Cité céleste qui ne laissent entrer Christian qu'après avoir reconnu le sceau sur son certificat.

En définitive, Bunyan s'est inspiré d'une métaphore chrétienne somme toute assez commune pour en faire un épisode-clé de son récit: chez lui, le passeport n'est pas une simple allusion au salut, mais un document de papier. Les prophètes congolais ont pris cette métaphore encore plus au pied de la lettre et ont confectionné de véritables passeports pour le Ciel. 


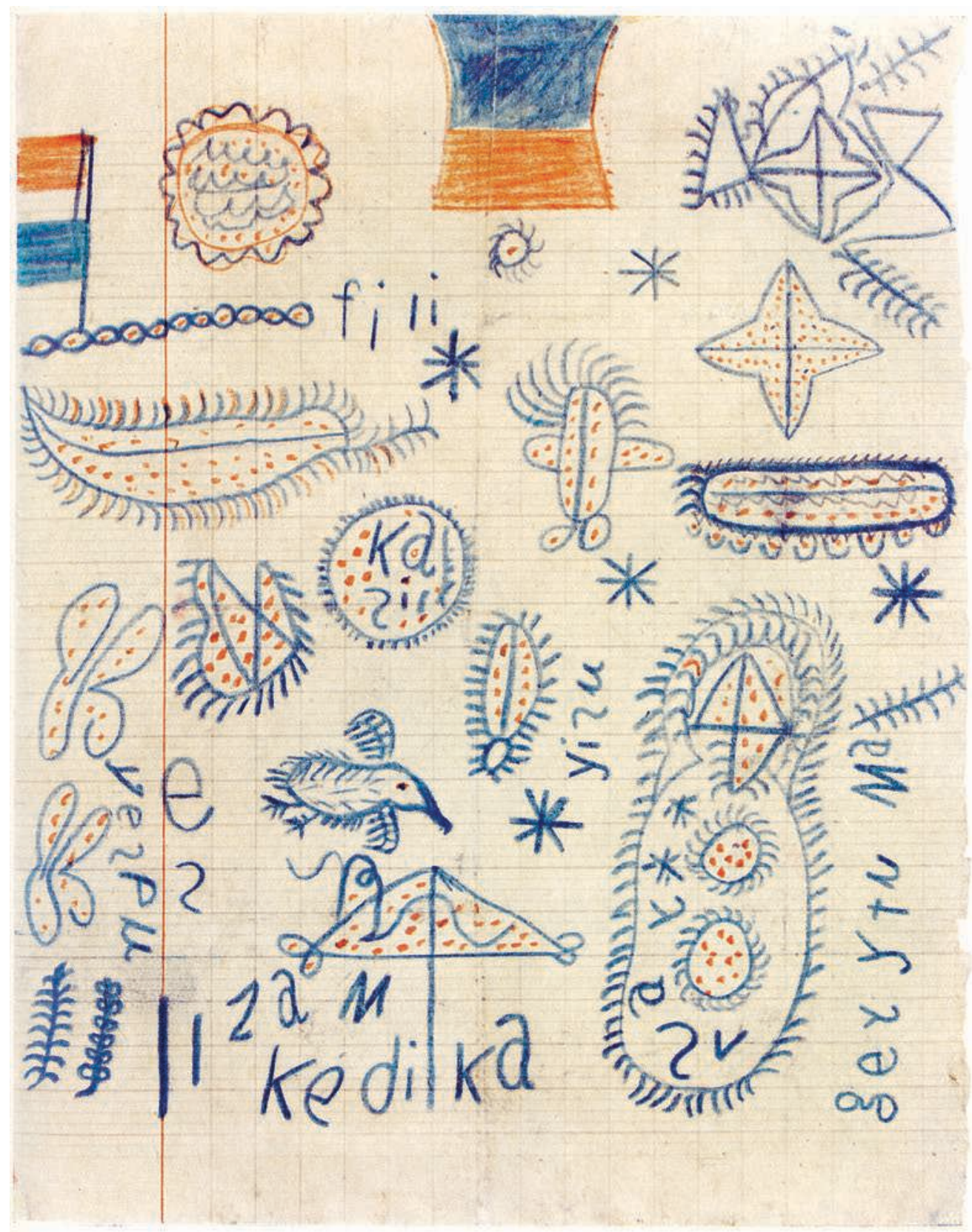

fig. 8

Passeport pour le Ciel, années 1940, in Andersson 1953: planche 3. Droits réservés. 


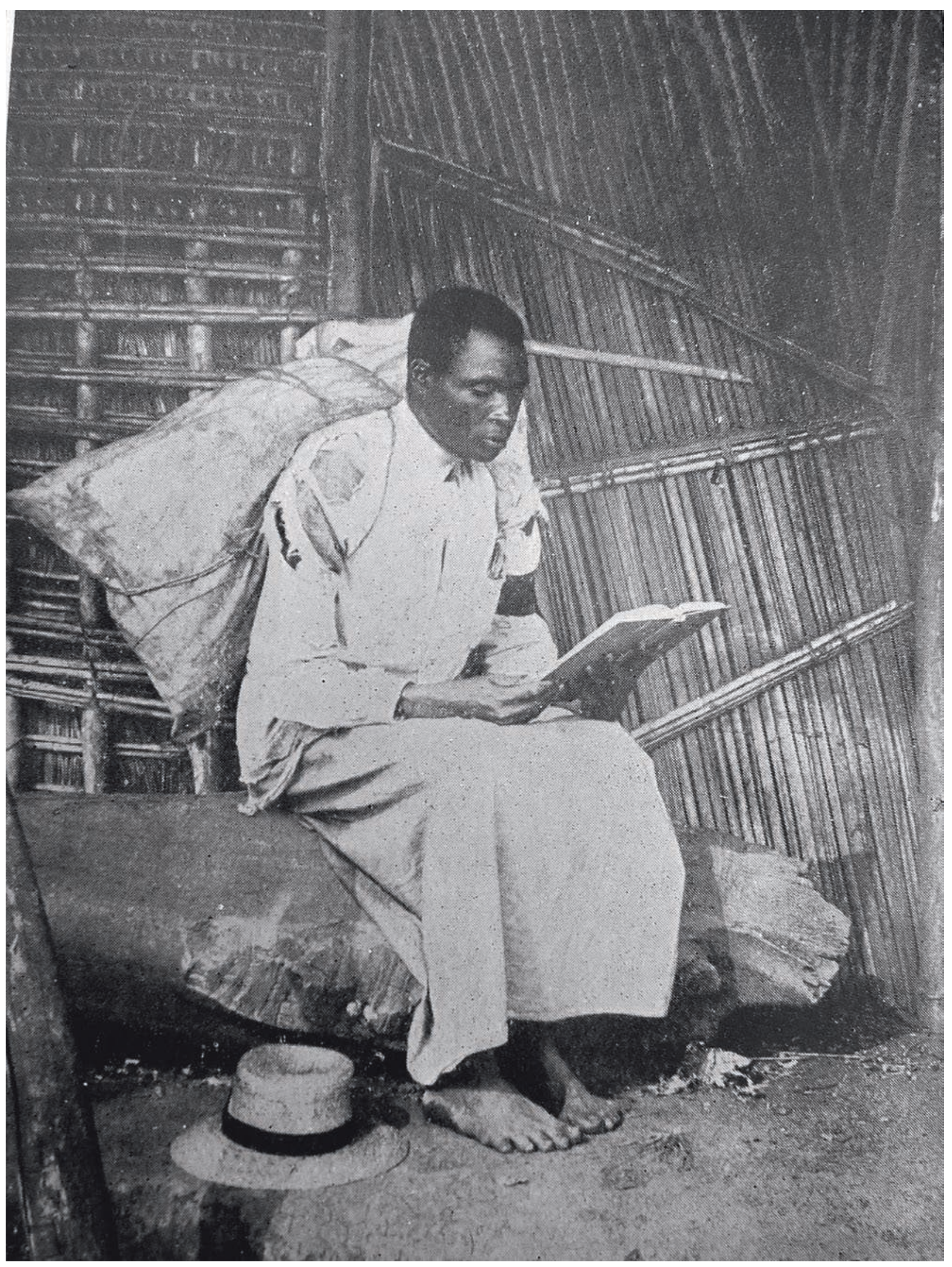

fig. 9

Illustration d'une édition du Voyage du Pèlerin en kikongo, 1920, Fonds de la School of Oriental and African Studies. Droits réservés. 


\section{PROPHÈTES, VOS PAPIERS !}

Le modèle des passeports pour le Ciel n'est pas seulement religieux, il est également administratif. Aux yeux des adeptes, ces documents font directement écho à leur expérience des papiers d'identité en tant que sujets colonisés. Au Congo belge, le livret d'identité est un document obligatoire. Il établit l'identité administrative de chaque individu: nom, prénom, date et lieu de naissance, nom des parents, profession, lieu de résidence, circonscription de rattachement. Les autres pages du livret incluent un relevé d'empreintes digitales, des renseignements sur le conjoint et les enfants, des certificats médicaux, une attestation de paiement de l'impôt, ainsi qu'un passeport de mutation. Tout déplacement de plus d'un mois hors de la circonscription est en effet soumis à autorisation. En AEF, il y a pareillement besoin d'un laissez-passer administratif. Les congrégations délivrent quant à elles des certificats de confiance à leurs catéchistes pour qu'ils puissent circuler dans leur zone d'évangélisation. Cette pratique, instaurée à la demande des autorités, sert à éviter que des catéchistes ralliés à la cause prophétique ne fassent du prosélytisme.

La délivrance des papiers d'identité fait partie de la routine des administrateurs territoriaux. L'un d'eux raconte qu'à chaque tournée en brousse, il doit transporter une malle de documents afin de s'acquitter de cette tâche (Domont 1988: 26). Les passeports de mutation sont une source de préoccupation pour le gouvernement, qui entend contrôler les déplacements des adeptes, accusés de propager des idées subversives dans toute la régiion. En 1943, un agent territorial écrit à son supérieur pour se plaindre des allées et venues des mpadistes à la frontière avec l'Angola:

Il serait désirable pour la tranquillité dans la région des frontières qu'il ne soit plus délivré de passeport de mutation pour les villages frontaliers à des gens qui n'y ont qu'y faire et n'y ont aucune famille. Les Angolais, désireux de revoir les leurs, devraient recevoir non pas un passeport de mutation, comme j'en ai vu, mais un passeport de sortie, comme préou par la législation ${ }^{31}$.

Dès le début de la colonisation, les Européens ont cherché à stopper les déplacements de populations afin de pouvoir les administrer plus facilement. Les livrets d'identité et les passeports de mutation participent de cette gouvernementalité coloniale: servant à maintenir les «indigènes » dans les limites de circonscriptions définies par l'État, ces documents sont une manifestation concrète du contrôle que celui-ci exerce sur leur vie. En 1943, au Congo français, quatre-vinǵts personnes venues de Sibiti souhaitaient se rendre à un office salutiste dans un village à une quarantaine de kilomètres de là; mais n'ayant pas de laissezpasser, elles sont arrêtées par la milice coloniale et sanctionnées.
Les papiers d'identité cristallisent la défiance des sujets colonisés à l'égard du pouvoir colonial. C'est notamment le cas parmi les partisans de Matsoua au Congo français: ils refusent les documents d'identité délivrés par le gouvernement, parfois au prix d'un séjour en prison. À la tête de l'Éǵlise matsouaniste à la fin des années 1940, Pierre Kinzonzi interdit aux fidèles de porter une carte d'identité non «signée» par Matsoua, contestant l'autorité de l'Administration en lui opposant celle, jugée supérieure, du leader congolais. Dans le discours messianique, le thème des papiers fait l'objet d'une inversion symbolique: en 1947, des gendarmes procèdent à l'interrogatoire d'un matsouaniste qui se fait appeler «Monseiǵneur». Celui-ci leur déclare:

\section{Lorsque les agents nous ont surpris, nous faisions une prière à l'effet de faire revenir parmi nous André Grenard, dit Matsoua. Nous sommes sûrs qu'il n'est pas mort. On ne nous a pas montré ses restes mor- tels, par conséquent il vit. Il se trouve en France et reviendra parmi nous, nous n'en connaissons pas le jour, mais il reviendra, nous en sommes certains. C'est notre Dieu, nous croyons en lui. C'est lui qui a gagné la guerre, ce n'est pas un autre. Il est si puissant qu'aucun Européen ne peut venir de France sans une carte signée de lui, ce n'est pas un laissez-passer, c'est une carte. Jamais un Européen ne peut arriver s'il n'a pas obtenu la carte signée d'André Grenard ${ }^{32}$.}

Les passeports prophétiques sont calqués sur les laissez-passer administratifs, comme le prouvent leur modèle formulaire et la mention systématique de la circonscription de rattachement: «NOM: Kilema. PÈRE: Seko. MÈRE: Kibongui. VILLAGE: Nsanǵi. POSTE: Kinkala.» Dans ce processus d'appropriation symbolique des documents officiels, la matérialité est également importante. En 1941, le commissaire provincial Morel s'étonne d'un passeport pour le Ciel en possession d'un adepte du prophète Bola-Mananǵa à Léopoldville. La carte est dactylographiée et conservée dans une enveloppe. Mais - et c'est ce qui trouble le commissaire - elle est en outre «établie sur du carton chamois, ressemblant à s'y méprendre à celui du bristol, de même espèce employée pour les fardes et les sous-mains en usage dans les bureaux du gouvernement ${ }^{33}$ ». Les autorités trouveront plusieurs exemplaires de cette série en bristol (fig. 2). L'enquête confirme que «les cartes en question ont bien été confectionnées sur du carton "Colonie", à l'aide d'une machine "Colonie" et dans les bureaux du gouvernement ${ }^{34}$ ».

Ce qui inquiète les autorités et justifie qu'une enquête ait été diligentée, c'est de découvrir que le prophétisme ne recrute pas seulement parmi la masse des «indigènes », mais aussi au sein de la petite élite des «évolués», ces aǵents auxiliaires dont l'État colonial a besoin pour assurer sa domination au quotidien. L'affaire est perçue comme une subversion de l'intérieur: des employés de bureau détournent le matériel
31. Fonds du Gouv. $G^{\text {al }}$ du Congo belge (GG16161).

32. Fonds du Gouv. Gal de l'AEF (5D203).

33. Fonds du Gouv. Gal du Congo belge (GG16203)

34. Le nom «Colonie» est en lui-même évocateur. Un autre modèle de machine à écrire utilisé par l'Administration et détourné par les adeptes s'appelle d'ailleurs «Royal». 
35. Fonds du Gouv. $G^{\text {al }}$ du Congo belge (GG7173). Dans le discours kimbanguiste «l'Amérique» est souvent invoquée comme une alliée contre les colonisateurs européens. Au début de la Seconde Guerre mondiale, «l'Allemagne» joue le même rôle. de l'Administration pour contrefaire des documents d'identité. Et il y a fort à parier que les auteurs des faits donnaient eux aussi à leur geste une signification subversive. L'usage de la machine à écrire préoccupe particulièrement les autorités : à chaque saisie d'un document dactylographié, elles tentent d'identifier la machine sur laquelle il a été tapé. En 1921, elles s'alarmaient déjà de la circulation d'une biographie de Kimbanǵu dactyloǵraphiée par ses «secrétaires» : lors de son procès, le document servira d'ailleurs de pièce à charge pour prouver la dangerosité du prophétisme.

La machine à écrire est l'outil par excellence de la bureaucratie. Plus encore que l'écrit manuscrit, son usaǵe par les adeptes prouve leur capacité à s'organiser en s'emparant des armes de leur adversaire pour les retourner contre lui. On ne saurait trouver meilleur exemple de la stratégie d'opposition mimétique du prophétisme à l'égard du pouvoir colonial : il s'aǵit de combattre l'Administration sur son propre terrain. Guy Bernard (1970) a soulignné l'importance de la bureaucratie dans les Éǵlises congolaises des années 1960. La situation n'est cependant pas la même avant et après l'indépendance. Après 1960, les Églises imitent les formes de la légitimité d'État pour obtenir sa reconnaissance officielle. Avant 1960, elles le font au contraire pour contester cette légitimité, à la manière des insurgés Mau-Mau qui, dans le Kenya des années 1950, prennent le maquis en emportant des registres, du papier carbone, des tampons et même de lourdes machines à écrire, autant d'artefacts bureaucratiques incarnant l'ordre colonial auquel ils s'opposent (Smith 1998).

Comme les documents administratifs dont ils s'inspirent, les passeports pour le Ciel sont presque toujours datés et comportent souvent un cachet ou une signature. Celle-ci se résume parfois à une initiale : un « $\mathrm{S}$ » pour Simon Kimbanǵu ou un « $\mathrm{A}$ » pour André Matsoua. Mais certains exemplaires sont signnés: «Simon Kimbanguu, Roi du Congo ». Comme l'a montré Béatrice Fraenkel (1992), la signature est un signe de validation qui investit l'écrit d'une force de type juridique: lorsqu'elle émane d'une autorité reconnue, elle fait du document un acte officiel. Les passeports pour le Ciel sont calqués sur le format de production des actes bureaucratiques, qui repose sur une chaîne de délégation d'autorité entre l'État et ses représentants: l'employé qui établit le document, l'autorité administrative dont on appose le cachet ou la signature, l'État qui en garantit in fine la validité. Signer les passeports au nom de Kimbangu revient à lui faire prendre la place du gouverneur général, le plus haut représentant de l'État dans la colonie. Cette subversion du modèle officiel est une façon de contester l'autorité coloniale en lui opposant celle du prophète, élevé au ranǵ de «Roi du Congo».

À travers sa signature, Kimbanǵu apparaît comme le véritable auteur des passeports, les secrétaires qui les ont établis étant de simples scribes. Dans la filiation de Benveniste (1969), j'entends par «auteur» un agent doté d'une autorité politique ou religieuse qui confère une force performative à ses paroles et ses écrits, les transformant ainsi en actes. Cette forme d'auctorialité se retrouve dans des lettres supposément écrites par Kimbanǵu. En 1946, un chef médaillé qui avait dénoncé Mpadi aux autorités quelques mois plus tôt reçoit une lettre de menace signée «Moi, Simon Kimbanǵu»:

Recevez de bonnes salutations, venant de moi que vous aves fait votre ennemi. C'est moi qui porte le nom de Kimbangu Simon. Je vous demande d'accuser réception de la lettre que je vous envoie quand vous l'aurez reçue. [...] Je ne suis pas mort dans le Haut-Congo où vous m'avez envoyé. Je suis parti en Amérique où l'on m'a fait Roi du Congo des Noirs. Moi, le Roi Kimbangu Simon, je suis sur le point d'arriver avec le Gouverneur général d'Amérique pour régner sur le pays jusqu'à jamais ${ }^{35}$.

Des lettres similaires circulent encore dans la région au début des années 1950, alors que Kimbangu est déjà mort. Ces apocryphes relèvent du genre messianique: Kimbangu y annonce l'avènement imminent de son royaume et la fin de l'ère coloniale. Ces lettres, comme les passeports pour le Ciel, témoignent du travail symbolique des adeptes pour élaborer un contremodèle de l'autorité coloniale. Par définition, l'autorité prophétique n'est jamais acquise, mais toujours à construire. Le «Kimbangu » qui signe des passeports ou écrit des lettres dans les années 1940-1950 n'est plus le prophète thaumaturge qu'il était en 1921. L'autorité de ce dernier reposait sur un charisme de la présence: Kimbangu prêchait en public, il «tremblait », parlait en lanǵues et guérissait par imposition des mains. Dans les années 1940, cela fait vinǵt ans qu'il n'est plus là et on le croit même mort et ressuscité: il n'est plus prophète, mais messie. Son autorité est désormais fondée sur un charisme de l'absence (ou de l'attente). Technologie de communication à distance, l'écrit est un médium adapté à ce mode singulier d'existence: le messie est physiquement absent, mais sa signature et ses lettres sont autant de traces indicielles de sa présence. Ces signes écrits ont l'avantage d'être manipulables par autrui, la dissociation entre le scripteur et l'auteur permettant de faire parler Kimbangu à la première personne. Ils sont en outre reproductibles, la copie et la circulation des documents permettant d'intensifier la présence du messie. L'auctorialité de l'écrit constitue ainsi une modalité importante de la construction d'une autorité messianique.

\section{UN MESSIANISME BUREAUCRATIQUE}

Les passeports pour le Ciel sont une parfaite illustration du mariage du messianisme et de la bureaucratie qui caractérise le prophétisme des années 1940 au Congoo. Ils s'inspirent à la fois de la culture missionnaire (le récit de Bunyan) et des pratiques de l'Administration (les livrets d'identité) en fusionnant ces deux 
modèles : l'allégorie religieuse fait écho à la réalité coloniale, le paradis devenant une métaphore de l'émancipation vis-à-vis des Européens. L'eschatologie revêt une signification politique: selon le prophète Mavonda Ntanǵu, ce sont les Blancs qui «barrent le chemin» des Noirs vers le Ciel. L'appropriation religieuse des papiers d'identité passe par un renversement symbolique typique du messianisme: à l'inverse des passeports de mutation, qui matérialisent l'assujettissement bureaucratique des populations colonisées et la restriction de leur liberté de circulation, les passeports pour le Ciel représentent une promesse de libération. L'opérateur qui rend possible cette subversion, c'est «Kimbangu, Roi du Congo »: non pas la personne réelle, mais la figure symbolique du messie que les adeptes opposent au pouvoir colonial en lui faisant prendre à la fois la place du Christ et celle du gouverneur général. Ce contre-modèle d'autorité met bien en lumière la relation de confrontation mimétique du prophétisme tant à l'égard de l'État que des congrégations reliǵieuses.

Ce messianisme bureaucratique correspond à un moment particulier de l'histoire du prophétisme au Congo. Ce n'est plus le prophétisme thaumaturgique des années 1920 qui s'appuyait sur le charisme personnel des ngunza inspirés par l'Esprit. Mais ce n'est pas encore l'Éǵlise kimbanguiste officielle, reconnue par l'État à la veille immédiate de l'indépendance, après avoir renoncé publiquement à toute forme d'engagement politique (Mélice 2009). L'Éǵlise kimbanguiste offre un bon exemple du processus d'institutionnalisation du prophétisme, qui se transforme alors en institution sacerdotale. Prise en main par des «évolués», elle se dote d'une organisation bureaucratique hiérarchisée qui encadre étroitement l'inspiration par l'Esprit: les «trembleurs» sont désormais accusés de dévoyer le kimbanguisme. Elle rèǵle également le problème de l'extinction du charisme en le transformant en bien héréditaire: ce sont les fils, puis les petits-fils de Kimbangu qui dirigent l'Éǵlise. Certains kimbanguistes, se sentant trahis par cette évolution, fonderont d'ailleurs des Éǵlises concurrentes, revendiquant leur continuité avec l'«esprit» prophétique des premiers temps.

De la sociologie historique des religions de Max Weber, on ne retient souvent que ses idéaux-types: la secte et l'Éǵlise, le prophète et le prêtre, le charisme et la bureaucratie. Ces dichotomies font cependant oublier que la réalité sociohistorique est essentiellement faite de formes hybrides et de compromis instables. Le messianisme bureaucratique des années 1940 en est un cas exemplaire. Contemporain de la Seconde Guerre mondiale, qui marque un tournant dans l'histoire coloniale, il se caractérise par un début d'institutionnalisation du prophétisme, par un fort anticolonialisme aux accents millénaristes (le départ des Européens devant coïncider avec le retour du Messie) et par une transformation du charisme en lien avec une nouvelle figure d'autorité à la croisée du politique et du religieux. L'écrit - en particulier l'écrit administratif - joue un rôle central dans la construction de cette autorité messianique, comme les passeports pour le Ciel le montrent bien. Ces documents prophé- tiques attestent d'une compréhension lucide des ressorts scripturaires de l'autorité coloniale. C'est parce que les colonisateurs ont massivement utilisé l'écrit pour asseoir leur domination que les sujets colonisés se sont approprié de manière mimétique ces siǵnes de pouvoir afin de s'opposer à elle.

Laboratoire d'anthropologie sociale, École normale supérieure julien.bonhomme@ens.fr 


\section{Bibliographie}

Amselle, Jean-Loup

2001 Branchements : anthropologie de l'universalité des cultures. Paris, Flammarion.

\section{Andersson, Efraim}

1958 Messianic Popular

Movements in the Lower Congo. Uppsala, Almqvist \& Wiksells.

\section{Austin, John L.}

1962 How To Do Things with Words: The William James Lectures Delivered at Harvard University in 1955. Oxford, Oxford University Press.

\section{Balandier, Georges}

1958 «Brèves remarques sur les "messianismes" de l'Afrique congolaise », Archives de sciences sociales des religions 5: 91-95.

\section{Benveniste, Émile}

1969 «Le censor et l'auctoritas», in Le Vocabulaire des institutions indo-européennes t. II : Pouvoir, droit, religion. Paris, Minuit: 143-151.

\section{Bernard, Guy}

1970 «Diversité des nouvelles Éǵlises congolaises », Cahiers d'études africaines 38 .

203-227.

Brinkman, Inge et Bostoen, Koen

2018 " "To Make Book":

A Conceptual Historical

Approach to Kongo Book

Cultures (Sixteenth-Nineteenth Centuries) », in Inge

Brinkman et Koen Bostoen (dir.),

The Kongo Kingdom: The

Origins, Dynamics and Cosmopolitan Culture of an African

Polity. Cambridge, Cambridge

University Press : 216-234

Covington-Ward, Yolanda

2016 Gesture and Power:

Religion, Nationalism, and Everyday Performance in Congo. Durham, Duke

University Press.

\section{Coyault, Bernard}

2019 «Efraim Andersson,

un missionnaire ethnologue

suédois en terrain prophétique

kongo (1929-1954)»,

Les Carnets de Bérose 12

[en ligne], disponible sur: https://www.berose.fr/ article1794.html (consulté le 21 avril 2020).

\section{Déléage, Pierre}

2013 Inventer l'écriture: rituels prophétiques et chamaniques des Indiens d'Amérique $d u$ Nord, XVII ${ }^{e}-X I X^{e}$ siècles. Paris, Les Belles Lettres.

2017 Lettres mortes: essai d'anthropologie inversée. Paris, Fayard.

2018 «Pseudographies: l'écriture révélée d'Emily Babcock », L'Homme 227-228 49-68.

\section{Domont, Jean-Marie}

1988 Un territorial au pays des sectes politico-religieuses du Bas-Congo pendant les années 1939-1945. Bruxelles,

Académie royale des siences d'Outre-Mer

\section{Fraenkel, Béatrice}

1992 La Signature: genèse d'un signe. Paris, Gallimard.

2006 «Actes écrits, actes oraux : la performativité à l'épreuve de l'écriture », Études de communication 29 69-93.

\section{Fromont, Cécile}

2011 «Under the Sign of the Cross in the Kingdom of Kongo », Res: Anthropology and Aesthetics 59-60 : 109-123

Hanks, William F.

2010 Converting Words: Maya in the Age of the Cross. Berkeley, University of California Press.

\section{Hawkins, Sean}

2002 Writing and Colonialism in Northern Ghana:

The Encounter between the LoDagaa and «the World on Paper». Toronto, University of Toronto Press.

\section{Hofmeyr, Isabel}

2004 The Portable Bunyan: A Transnational History of «The Pilgrim's Progiress». Princeton, Princeton University Press.

Hull, Matthew S.

2012 Government of Paper: the Materiality of Bureaucracy in Urban Pakistan. Berkeley,

University of California Press.

\section{Jaffré, Côme}

1934 "L'Afrique aux Africains ou le "Ngounzisme" au Conǵo ", Études. Revue catholique d'intérêt général 218 (122): 651-664.

\section{Kirsch, Thomas G.}

2008 Spirits and Letters: Reading, Writing, and Charisma in African Christianity. New York, Bergohahn.

\section{MacGaffey, Wyatt}

1986 Religion and Society in Central Africa: the BaKongo of Lower Zaire. Chicago, University of Chicago Press.

Madeira Santos, Catarina

2010 «Administrative Knowledge in a Colonial Context: Angola in the Eighteenth Century », British Journal for the History of Science 43 (4) : 539-556.

\section{Mary, André}

2009 Visionnaires et prophètes de l'Afrique contemporaine. Transe initiatique, culture de la transe et charisme de délivrance. Paris, Karthala.

\section{Mélice, Anne}

2009 «Le kimbanguisme et le pouvoir en RDC: entre apolitisme et conception théologico-politique», Civilisations 58 (2) : 59-80.

\section{Probst, Peter}

1989 «The Letter and the Spirit: Literacy and Religious Authority in the History of the Aladura Movement in Western Nigeria », Africa 59 (4) 478-495.

\section{Ryckmans, André}

1995 André Ryckmans, un territorial du Congo belge: lettres et documents, 1954 1960. Paris, L'Harmattan.

\section{Sinda, Martial}

1974 Le Messianisme congolais et ses incidences politiques. Paris, Payot.

Smith, James H.

1998 «Njama's Supper: The Consumption and Use of Literary Potency by Mau Mau Insurgents in Colonial Kenya", Comparative Studies in Society and History 40 (3) 524-548.

\section{Street, Brian V.}

1984 Literacy in Theory and Practice. Cambridge, Cambridge University Press.

\section{Vellut, Jean-Luc (éd.)}

2005 Simon Kimbangu: 1921 : de la prédication à la déportation. Les sources. Volume I: Fonds missionnaires protestants (1). Alliance missionnaire suédoise. Bruxelles, Académie royale des sciences d'outre-mer.

2010 Simon Kimbangu. 1921 : de la prédication à la déportation. Les sources. Volume I: Fonds missionnaires protestants (2). Missions baptistes et autres traditions évangéliques. Le pays kongo entre prophétismes et projets de société. Bruxelles,

Académie royale des sciences d'outre-mer.

\section{Weber, Max}

2014 [1914] La Domination, Yves Sintomer (éd.), trad. de l'allemand par Isabelle Kalinowski. Paris, La Découverte.

\section{Yates, Barbara A.}

1987 «Knowledge Brokers: Books and Publishers in Early Colonial Zaire», History in Africa 14: 311-340.

\section{Ci-contre et ouverture}

Passeport pour le Ciel années 1940, in Andersson 1953 planche 3 (détail). Droits réservés. 
